\title{
A Prospective Study Assessing the Audiological Outcome of Tympanoplasty with Autologus Platelet Rich Plasma
}

\author{
NR Ankle, Rajesh Radhakrishna Havaldar, Sweta Sinha* and Vijay Yeramalla \\ Department of ENT \& Head and Neck Surgery, J.N.Medical College, KLE Academy Of Higher Education \&Research, Belagavi, \\ Karnataka, India
}

*Corresponding author: Sweta Sinha, Post Graduate Resident, Department of ENT \& Head and Neck Surgery, J.N.Medical College, KLE Academy Of Higher Education \& Research, Belagavi, Karnataka, India

\section{ARTICLE INFO}

Received: 蔧 May 20, 2021

Published: 蔧 June 02, 2021

Citation: NR Ankle, Rajesh Radhakrishna Havaldar, Sweta Sinha, Vijay Yeramalla. A Prospective Study Assessing the Audiological Outcome of Tympanoplasty with Autologus Platelet Rich Plasma. Biomed J Sci \& Tech Res 36(2)-2021. BJSTR. MS.ID.005819.

\begin{abstract}
A prospective observational study in 90 patients of age group of 15 to 50 years with chronic suppurative otitis media attending the outpatient department of ENT at a tertiary care referral centre was conducted. All patients during the study period underwent Tympanoplasty with Platelet Rich Plasma for assessing the hearing gain. The objective of this study was to assess the benefits of platelet rich plasma in terms of improvement in hearing after tympanoplasty. In this prospective observational study using autologous Platelet Rich Plasma; patients showed a significant audiological hearing improvement at 3 months postoperative period compared to preoperative audiological assessment. Thus, we can conclude that Tympanoplasty not only aims to correct the damaged tympanic membrane, but also aids in improvement in hearing by reducing the amount of conductive hearing loss. The use of Autologous Platelet rich plasma helps in adequate sealing of the graft material along with the freshened edges of the perforation, thereby accelerating the graft uptake, promoting faster healing and hearing improvement.
\end{abstract}

Keywords: Tympanoplasty; Autologous Platelet Rich Plasma; Hearing Improvement; Audiometry; Growth Factors

\section{Introduction}

Tympanoplasty is a surgical method for eradication of infection and maintaining middle ear functions. Temporalis fascia is a common graft material used in tympanoplasty since 1960; however, there are other available graft materials such as cartilage perichondrium, areolar tissue, vein, fat and periosteum [1]. The success rate of graft uptake and improvement in hearing in tympanoplasty varies in different studies. Various studies have been conducted using platelet rich plasma to improve the surgical outcomes in tympanoplasty and hearing improvement [2]. In an era of regenerative medicine where we discuss of cloning, stem cells therapy or platelet rich plasma to regenerate or promote growth of body tissue or organ, the Platelet Rich Plasma (PRP) is easy to procure and its addition in middle ear surgery would possibly help in more improvement of hearing apart from early healing and better success in tympanoplasty. PRP is easiest to procure and to use in human body. Since it is autologous practically it does not have any significant side effect $[3,4]$. Platelet or thrombocytes conventionally known for blood clotting, releases many growth factors at the site of injury and thus, promotes repair and healing. The body has an inbuilt power of healing at the site of injury whether traumatic or iatrogenic and hence if we aggravate the healing by application of growth factors at the same site, undoubtedly repair will be much better. We can define PRP as a volume of autologous plasma of blood which has been enriched with platelets and growth factors. The technique to condense and provide growth factors in the form of PRP at the site of injury and thereby its assessment in hearing improvement has been undertaken in the present study.

\section{Objective}

To assess the benefits of platelet rich plasma in terms of improvement in hearing after tympanoplasty. 


\section{Material and Methods}

\section{Study Design}

Prospective observational study.

\section{Study Period}

January 2019 to June 2020.

\section{Source of Data}

All patients between age group of 15 to 50 years with chronic suppurative otitis media attending the outpatient department of ENT at a tertiary care referral centre during the study period and willing to undergo surgery for the same were included in the study.

\section{Sample Size}

90 patients.

\section{Inclusion Criteria}

All the patients above the age group of 10 years, with no evidence of active infection in the ear, nose, throat and Central Perforation of the Pars Tensa of the tympanic membrane with dry ear for a minimum period of 3 weeks before the day of operation.

\section{Exclusion Criteria}

Patients with sensorineural or mixed hearing loss, attico-antral disease and tympanosclerosis were excluded from the study.

\section{Methodology}

All patients underwent type 1 tympanoplasty supplemented by platelet rich plasma. Pure Tone Audiometry was done before the surgery and 3 months after the surgery to evaluate the hearing outcome.

\section{Results}
a. Total number of patients- 90
b. $\quad$ Male: Female- $1.67: 1$
c. Mean age of the patients- 42 years

Table 1 depicts the size of the perforation wherein maximum patients presented with medium central perforation which was 54 out of the total patients. Figure 1 shows the distribution of patients according to the site of perforation. About $31.11 \%$ patients had perforation inolving all quadrants of the tympanic membrane and abot $7 \%$ patients had perforation involving only the inferior quadrant. Table 2 shows the hearing assessment at various time intervals wherein the maximum patients who presented with moderate degree hearing loss pre operatively improved post operatively and the number of patients changed form 54 patients pre operatively to 47 patients post operatively. At 6 weeks, 4 patients presented with ear discharge. At 3 months, 2 patients out of the total 90 patients presented with ear discharge and 6 patients failed to follow up.

\section{Percentage of patients according to site of perforation}

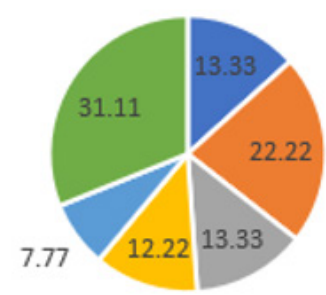

- Anterior | Antero-inferior | Posterior " Postero-inferior = Inferior | All quadrants

Figure 1: Percentage of patients according to site of perforation.

Table 1: Size of perforation.

\begin{tabular}{|c|c|c|}
\hline Size of perforation & No. of patients & \% of patients \\
\hline Medium Central Perforation & 54 & $28 \%$ \\
\hline Large Central Perforation & $81.11 \%$ \\
\hline Small Central Perforation & $8.88 \%$ \\
\hline
\end{tabular}


Table 2: Hearing assessment at various time intervals.

\begin{tabular}{|c|c|c|c|}
\hline & \multicolumn{3}{|c|}{ Number of patients } \\
\cline { 2 - 4 } & Pre-operative & At 6 weeks & At 3 months \\
\hline Normal $(<15 \mathrm{~dB})$ & - & - & 37 \\
\hline Mild $(26-40 \mathrm{~dB})$ & 27 & 47 & 41 \\
\hline Moderate $(41-55 \mathrm{~dB})$ & 54 & 5 & 4 \\
\hline Moderately-severe $(56-70 \mathrm{~dB})$ & 9 & 0 & 0 \\
\hline Severe $(71-90 \mathrm{~dB})$ & 0 & 0 & 0 \\
\hline Profound $(>90 \mathrm{~dB})$ & 0 & 4 & 2 \\
\hline Residual ear discharge & 0 & 0 & 6 \\
\hline Loss to follow up & 0 & 90 & 90 \\
\hline Total & 90 & & \\
\hline
\end{tabular}

\section{Discussion}

Platelet releasates have been used to treat wounds since 1985 . The application of platelet-rich plasma has been documented in many fields, such as orthopaedics, dentistry, and cosmetic and plastic surgery. In otology, the efficacy of platelet-rich plasma has been demonstrated in tympanoplasty procedures [5]. Yeo et al. investigated the effect of platelet-derived growth factor-AA on the healing process of tympanic membrane perforation in rats. The results revealed a speeding up of the healing process of the tympanic membrane defect, an improved rate of healing, and fewer atrophic changes in the healed tympanic membrane. This is explained by the fact that platelet-derived growth factor-AA promotes connective tissue growth [6]. Platelet-rich plasma accelerates the healing of tympanic membrane perforation following myringoplasty. It prevents graft displacement or shrinkage, especially in wet grafts, with its sealant property. Platelet-rich plasma improves the overall success rate of myringoplasty. Furthermore, it has no noticeable side effects [7].

Conductive hearing loss is the most common finding in our study. Ediale, et al. [8] suggested that this is due to loss of membrane surface area which is doing the amplification of sound waves. High prevalence of conductive hearing loss was seen by studies done by Maharajan, et al. [9] and Bhusal, et al. [10,11] in a study of 80 patients observed a mild hearing loss in $37.70 \%$ patients and $11.47 \%$ had moderate hearing loss. The moderately severe hearing loss was seen in $4.91 \%$ cases of mucosal disease. Muftah, et al. [12] in their study reported that mild hearing loss was seen in $37.3 \%$ patients and moderate loss in $25.5 \%$ patients. Severe hearing loss was seen in $3.9 \%$ patients. The insignificant difference in mean hearing loss of antero-inferior and postero-inferior quadrant perforation might be because of round window niche location. These perforations are not much effective in removing round window phase difference. In between perforations involving two quadrants located over anterosuperior + anteroinferior or postero-inferior + postero-superior quadrants, the loss is greater in posterior perforations as they cause loss of round window phase difference. Mehta, et al. [13] in their experimental model study and later clinical work contradicted the popular concept of posterior perforations causing higher hearing loss than anterior perforations.

The current study shows that age and gender do not seem to have any bearing on the postoperative hearing improvement, which are in agreement with the results of several other studies [14-16]. Despite greater preoperative hearing loss in larger size perforations, postoperative hearing gain was mostly better with smaller size perforations [17]. The explanation for better hearing improvement in smaller size perforations, especially if associated with shorter disease duration, may be the less extent of pathological changes in the middle ear.18However, it is worth to mention that, these two factors were taken into consideration by the author in advance in this study, as the inclusion/exclusion criteria required that the middle ear mucosa be without any pathological changes, and duration of perforation be less than 1 year. Other studies, however, have concluded that there is no correlation between the size of the perforation and postoperative hearing gain [16]. In a study conducted by Masoumeh Saeedi et. al., it was noted that application of PRP-enriched gel foams make chronic TM perforation heal more efficiently than gel foam alone [18]. In a study done by Rajendran Dinesh Kumar in 2017 on application of Platelet Rich Fibrin Matrix to Repair Traumatic Tympanic Membrane Perforations, it was found that the mean pre-operative air-bone gap was $20.2 \mathrm{~dB}$. On post-operative day 45 , the mean improvement in the air- bone gap was $12.1 \mathrm{~dB}$; membrane quality in TM healing was better in patients treated with PRF as compared to not using it [19].

\section{Conclusion}

Tympanoplasty not only aims to correct the damaged tympanic membrane, but also aids in improvement in hearing by reducing the amount of conductive hearing loss. The use of PRP helps in adequate sealing of the graft material along with the freshened edges of the perforation, thereby accelerating the graft uptake and promoting faster healing. Due to the presence of growth factors in the natural composition of autologous PRP the chances of graft displacement 
failure is minimal. The improvement in hearing could also be acknowledged due to the fact that the healing takes far lesser time compared to conventional methods. This also gives a subjective sense of well-being to the patient and aids in confirmation of the same when verified by oto-endoscopy and pure tone audiometry.

\section{Funding}

None

\section{Conflicts of Interest}

None.

\section{Ethics Approval}

Approval was obtained from institutional ethics committee. The procedures used in this study adhere to the tenets of the Declaration of Helsinki.

\section{Consent to Participate}

Written informed consent was obtained from the relatives/ legal guardians of the study participant.

\section{References}

1. Flint PW, Haughey BH, Robbins KT, Thomas JR, Niparko JK, et al. (2014) Cummings otolaryngology-head and neck surgery. Elsevier Health Sciences.

2. El-Anwar MW, EL-Ahl MAS, Zidan AA, Yacoup MARAS (2015) Topical use of autologous platelet rich plasma in myringoplasty. Auris Nasus Larynx 42(5): 365-368.

3. Vannini F, Di Matteo B, Filardo G, Kon E, Marcacci M, et al. (2014) Platelet-rich plasma for foot and ankle pathologies: a systematic review. Foot Ankle Surg 20(1): 2-9.

4. Zhu Y, Yuan M, Meng HY (2013) Basic science and clinical application of platelet-rich plasma for cartilage defects and osteoarthritis: a review. Osteoarthr Cartil 21(11): 1627-1637.

5. Driver VR, Hanft J, Fylling CP, Beriou JM (2006) Autologel Diabetic Foot Ulcer Study Group. A prospective, randomized, controlled trial of autologous platelet-rich plasma gel for the treatment of diabetic foot ulcers. Ostomy Wound Manage 52: 68-70,72,74.

\section{ISSN: 2574-1241}

DOI: $10.26717 /$ BJSTR.2021.36.005819

Sweta Sinha. Biomed J Sci \& Tech Res

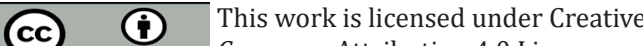
Commons Attribution 4.0 License

Submission Link: https://biomedres.us/submit-manuscript.php
6. Yeo SW, Kim SW, Suh BD, Cho SH (2000) Effects of platelet-derived growth factor-AA on the healing process of tympanic membrane perforation. Am J Otolaryngol 21(3): 153-160.

7. Carter MJ, Fylling CP, Parnell LK (2011) Use of platelet rich plasma gel on wound healing: a systematic review and meta-analysis. Eplasty 11: e38.

8. Ediale J, Adobamen PROC, Ibekwe TS (2018) Audiometric assessment of adolescents and adults with tympanic membrane perforation in Benin City. Int J Otorhinolaryngol Head Neck Surg 4(4): 901-906.

9. Maharajan M, Kafle P, Bista M, Shrestha S, Toran KC (2009) Observation of hearing loss in patients with chronic suppurative otitis media tubotympanic type. Kathmandu Univ Med 7(28): 397-401.

10. Bhusal CL, Gurugain RPS, Shrivastav RP (2006) Size of tympanic membrane perforation and hearing loss. J Nepal Med Assoc 45(161): 167-172.

11. Kabdwal N, Vashney S, Bist SS, Bhagat S, Mishra S (2013) Pre and postoperative evaluation of hearing in chronic suppurative otitis media. Indian J Otol 19(4): 164-168.

12. Muftah S, Mackenzie I, Faragher B, Brabin B (2015) Prevalence of chronic suppurative otitis media (CSOM) and associated hearing impairment among school-aged children in Yemen. Oman Med J 30(5): 358-365.

13. Mehta RP, Rosowski JJ, Voss SE, O'Neil E, Merchant SN (2006) Determinants of hearing loss in perforations of the tympanic membrane. Otol Neurotol 27(2): 136-143.

14. Yung MW (1983) Myringoplasty: hearing gain in relation to perforation site. J Laryngol Otol 97(1): 11-17.

15. Shrestha S, Sinha BK (2006) Hearing results after myringoplasty. Kathmandu Univ Med J (KUMJ) 4(4): 455-459.

16. Karela M, Berry S, Watkins A, Phillipps JJ (2008) Myringoplasty: surgical outcomes and hearing improvement: is it worth performing to improve hearing? Eur Arch Otorhinolaryngol 265(9): 1039-1042.

17. Lee P, Kelly G, Mills RP (2002) Myringoplasty: Does the size of the perforation matter? Clinical otolaryngology and allied sciences 27(5): 331-334.

18. Kumar TVV V (2015) Evaluation of various graft materials in myringoplasty. Int J Pharm Bio Sci 6: 700e723.

19. Kumar RD (2019) Application of Platelet Rich Fibrin Matrix to Repair Traumatic Tympanic Membrane Perforations: A Pilot Study. Indian J Otolaryngol Head Neck Surg 71(2): 1126-1134.

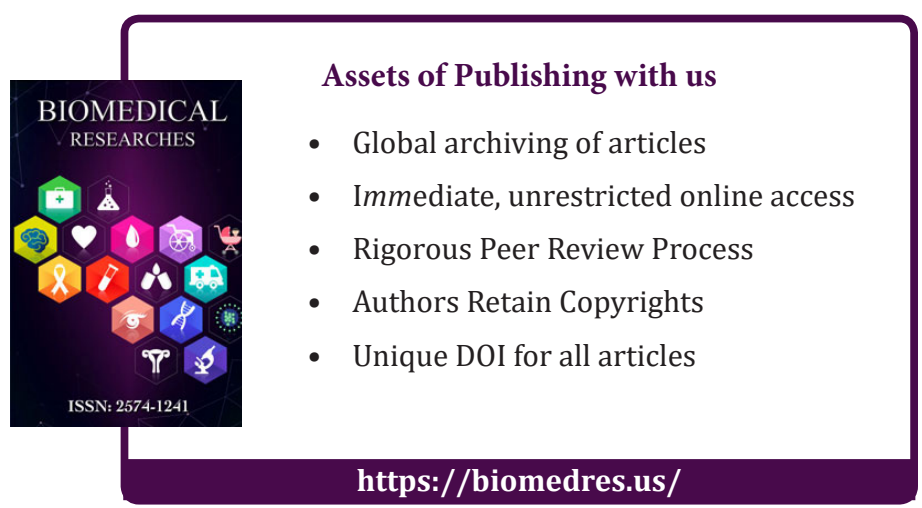

